\title{
LACAN COM MARX EM WALL STREET, UM DIA ANTES DO FIM: UMA ANÁLISE DE MARGIN CALL A PARTIR DO ENCONTRO DA TEORIA DOS DISCURSOS LACANIANA E DA CRÍTICA DA ECONOMIA POLÍTICA MARXIANA
}

JOSÉ RODRIGUES

José Rodrigues Universidade Federal Fluminense (UFF), Professor Titular da Faculdade de Educação, Niterói/RJ, Brasil.
RESUMO: A partir da teoria dos discursos de Jacques Lacan, em diálogo com a teoria do valor de Karl Marx, o texto analisa o filme Margin Call, que retrata ficcionalmente o desencadeamento da atual crise capitalista, com a quebra do banco Lehman Brothers, em 2008. Dentre as questões que o texto coloca, além do papel do discurso da ciência na sociedade atual, destaca-se a persistência do discurso capitalista.

Palavras-chave: teoria dos discursos de Lacan; discurso capitalista e resistência à Psicanálise; Psicanálise e marxismo.

Abstract: Lacan with Marx in Wall Street, a day before the end: an analysis on Margin Call from the confluence of the Lacanian theory of speeches and the Marxian critique of political economy. From the theory of the speech of Jacques Lacan, in dialog with Karl Marx's theory of value, the text analyses the film Margin Call, which fictionally portraits the unchaining of current capitalist crisis, with the bankruptcy of the Lehman Brothers bank, in 2008. Amongst the issues posed by the text, besides the role of the discourse of the science in the current society, the persistence of the capitalist speech is to be evidenced.

Keywords: Theory of Speech of Lacan; Capitalist Speech and Resistance to Psychoanalysis; Psychoanalysis and Marxism.

DOI - http://dx.doi.org/10.1590/1809-44142017003008 
- 15 de setembro de 2008, jornais de todo o mundo tornaram pública a falência do banco de investimentos ELehman Brothers, uma empresa global de serviços financeiros, com sede em Nova lorque. A partir desta falência, muitas outras aconteceram em cadeia, e até mesmo o governo republicano e conservador de George W. Bush empreendeu uma gigantesca onda de estatizações: das firmas de hipoteca Fannie Mae e Freddie Mac, filhas da grande depressão de 1929, até a General Motors. Iniciou-se, assim, a atual crise mundial do capitalismo, da qual não se enxerga saída.

No final de 2011, estreou o filme Margin Call (Margin Call, de J. C. Chandor, EUA, 2011), que, no Brasil, recebeu o interessante subtítulo $O$ dia antes do fim. Na ficção, a história se desenrola praticamente toda na sede de um grande banco de investimentos, principalmente durante a madrugada, nas horas que antecedem o "fim". A maior parte das cenas retrata corredores e salas vazias, além das ruas de Nova lorque, igualmente desertas.

O filme inicia-se com a demissão de um grande contingente de funcionários do banco, inclusive do analista sênior de risco, Eric Dale (Stanley Tucci), responsável pela operação de um complexo algoritmo que mede o risco das manobras financeiras da empresa. Contudo, antes de ser literalmente posto para fora do prédio, Dale entrega a um de seus ex-subordinados, Peter Sullivan (Zachary Quinto), um pen drive, com um alerta: "Tenha cuidado".

Sullivan, após o horário de expediente, descobre que, segundo o modelo matemático, a empresa está virtualmente falida. A partir daí, durante a madrugada, Sullivan avisa ao colega Seth Bregman (Penn Badgley), que chama o seu novo superior, Will Emerson (Paul Bettany), que, por sua vez, convoca seu próprio superior, Sam Rogers (Kevin Spacey), que chama outro superior, e assim sucessivamente, até chegar ao topo da pirâmide: John Tuld (Jeremy Irons), que reúne todo o conselho executivo do banco.

A firma, de fato, está de posse de títulos de hipoteca conhecidos como subprime, ou seja, hipotecas que dificilmente serão pagas. Na verdade, a empresa já ultrapassara todas as margens de segurança financeira. $A$ questão que se coloca a partir daí é como se livrar do "mico", antes que o mercado e o governo percebam o rombo financeiro. A história desdobra-se entre cooperação e escaramuças, cada um tratando de salvar a si mesmo e tentando não entrar em pânico, mesmo que o prejuízo de bilhões de dólares e o colapso do mercado financeiro global estejam batendo à porta.

O presente texto intenciona, primeiramente, analisar o filme Margin Call, através de algumas de suas cenas. Para empreender tal análise, recorre à crítica da economia política de Karl Marx, de um lado, e à teoria do laço social, de Jacques Lacan, de outro. No que tange à teoria lacaniana dos discursos, o texto busca defender uma tese sobre a persistência deste discurso que não faz laço - o mortífero pseudodiscurso capitalista.

Nesse sentido, o texto também pretende introduzir o leitor nestas duas perspectivas teóricas, aparentemente tão distantes e tomadas inclusive, por vezes, como antitéticas. Ao fazer isso, portanto, pretendemos nos unir ao movimento de atualização daquele impulso que animou o freudo-marxismo, tratando-se agora de um freudismo renovado pelo ensino de Lacan (SAFATLE, 2008, p. 20).

\section{O LAÇO SOCIAL SEGUNDO LACAN: OS QUATRO DISCURSOS1}

Sem dúvida, a psicanálise vem sendo construída no um a um. Mas, não é menos verdadeiro afirmar que a esta nunca foi estranha a preocupação com o laço social, como nos ensinou Freud, em Psicologia das massas e análise do Eu:

Na vida psíquica do ser individual, o outro é via de regra considerado enquanto modelo, objeto, auxiliador e adversário, e, portanto, a psicologia individual é também, desde o início, psicologia social, num sentido ampliado, mas inteiramente justificado. (FREUD, 1921/2011, p. 14)

\footnotetext{
${ }^{1}$ Dadas as limitações de espaço, não poderemos tratar de forma exaustiva a teoria dos discursos. Nesse sentido, dentre as incontáveis referências, indicamos os verbetes Discurso do analista, de A. Yacoi; Discurso capitalista, de A. Aflalo; Discurso da histérica, de H. Caldas; Discurso do mestre, de S. Geller; e Discurso universitário, de Tudanca; todos reunidos em Scilicet: Os objetos a na experiência psicanalítica (AMP, 2008), além de Bernardes (2003), Alberti (s/d), Soueix (1997) e, obviamente, os textos lacanianos.
} 
Lacan com Marx em Wall Street, um dia antes do fim: uma análise de Margin Call a partir do encontro da teoria dos discursos lacaniana e da crítica da economia política marxiana

Destacam-se nesta direção, pelos menos quatro grandes obras freudianas, a saber, Totem e tabu, Psicologia das massas e análise do Eu, O mal-estar na civilização e Moisés e o monoteísmo (Freud, 1913, 1921/2006, 1929/2011, 1939/2006). Talvez não por acaso, a elaboração e a publicação dessas obras possa ser relacionada às circunstâncias mais ou menos críticas do assim chamado movimento psicanalítico, ou seja, da institucionalização e da permanência da psicanálise. Nesse sentido, talvez não seja forçoso afirmar que tais textos têm uma forte preocupação política: o que cria e mantém o laço social?

De forma análoga, numa situação histórica complexa - encruzilhada de guerras de libertação, do Vietnam e da Argélia, crises sociais, inclusive aquela nomeada por uma data, o Maio de 1968, desalojado da Escola Normal Superior - Jacques Lacan, entre 1969 e 1970, no seu Seminário 17: o avesso da psicanálise (LACAN, 1969-70/1992), formula sua concepção de laço social, ou seja, de discurso, uma estrutura que pode inclusive dispensar as palavras, mas nunca a linguagem:

É que sem palavras, na verdade, ele pode muito bem subsistir. Subsiste em certas relações fundamentais. Estas, literalmente, não poderiam se manter sem a linguagem. Mediante o instrumento da linguagem instaurase um certo número de relações estáveis, no interior das quais certamente pode inscrever-se algo bem mais amplo, que vai bem mais longe do que as enunciações efetivas. (LACAN, 1969-70/1992, p. 10-1).

Com efeito, Lacan sistematiza o laço social, sob forma uma lógico-algébrica, em quatro discursos: o do senhor (DS) ${ }^{2}$, o da histérica (DH), o do analista (DA) e o universitário (DU).

É no ano anterior, ou seja, em O Seminário, livro 16: de um Outro ao outro, que se encontram as bases necessárias à produção teórica dos discursos (LACAN, 1968-69/2008). É no seminário de 1968-69, que Lacan traça a homologia entre a mais-valia de Marx e o seu mais-de-gozar. Com efeito, a noção lacaniana de discurso condensa aparelho de linguagem e economia pulsional, incluindo na estrutura o próprio objeto que se destaca do significante. É nesse sentido que o discurso é uma forma de tratar o gozo (BECKER, 2010).

O matema primeiro da série dos discursos, ou seja, sua matriz, é aquele que formaliza simultaneamente o discurso do próprio Inconsciente, de um lado, e a definição lacaniana de significante - "o significante é aquilo que representa o sujeito para o significante" -, ou seja, o discurso do senhor:

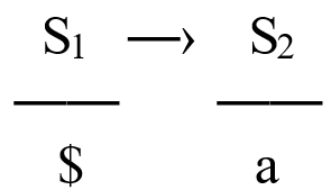

Uma das cenas de Margin Call pode ilustrar o discurso do senhor. O senhor John Tuld (JT), executivo chefe do banco, entra na sala de reunião, na qual todos o aguardam, cumprimenta o grupo, pede desculpas pela hora e ordena: “Alguém pode me dizer o que está acontecendo aqui?". Jared Cohen começa a falar em relatórios, números, mas é interrompido por Tuld, que diz:

JT: Jared, é cedo para isso. Explique na nossa língua. Quero falar com a pessoa que organizou isso. Senhor Sullivan, não é? Ele fala a nossa língua? Eu quero falar com o analista que tropeçou nessa bagunça.

Cohen, então, aponta para Sullivan, a quem Tuld se dirige:

JT: Senhor Sullivan, bom dia. Poderia me falar sobre o que acha que está acontecendo? Por favor, fale como se estivesse falando com uma criança ou com um golden retriever. Não foi a minha inteligência que me trouxe até aqui. Eu garanto isso. [...] Qual é a natureza do problema?

O discurso do senhor remete diretamente à dialética hegeliana do senhor e do escravo, apresentada em A fenomenologia do espírito (LACAN, 1969-70/1992, p. 33; HEGEL, 1807/1992). Em poucas palavras, o senhor (ou a lei, a tradição) dirige-se ao escravo (ou ao saber), que possui um saber sobre o trabalho, pondo-o a trabalhar. Deste trabalho, algo é produzido. A verdade que o senhor é castrado, ou seja, portador de uma falta, está velada para ambos. A condição oculta da castração do senhor é fundamental para que este laço

\footnotetext{
${ }^{2}$ Há várias possíveis traduções de maître: mestre, senhor, amo, dono. Neste texto, optamos por senhor.
} 
social permaneça. Em Hegel, a suposta superioridade do senhor se apoia em sua coragem de enfrentar a morte.

Na cena em questão, após a explicação técnica das manobras financeiras que levaram a empresa à beira do abismo, Tuld pergunta:

Então, está me dizendo que a música está prestes a parar, e estaremos segurando o maior saco de excremento aromático, jamais juntado na história do capitalismo?

Após ouvir algumas considerações sobre o cenário futuro e o modelo matemático, o senhor Tuld, novamente fala:

Quer saber por que estou nesta cadeira, com vocês todos? Quer dizer, por que eu ganho uma grana preta? Estou aqui para prever o que vai acontecer com a música daqui a uma semana, um mês, um ano, nada mais. E parado aqui esta noite, eu temo não mais estar ouvindo absolutamente nada. Apenas silêncio. Agora que sabemos que a música parou, o que podemos fazer?

Os executivos, particularmente Sam Rogers, tentam convencer o senhor Tuld de que as formas de se enfrentar o problema serão desastrosas para a empresa, para o mercado e que até mesmo o $\mathrm{FBI}$ entrará no caso. A Morte, em seu silêncio, espreita. Mas, o senhor não a teme: "Se eu te obrigasse, como você faria?". Em seguida, dá novas ordens, inclusive: "Venda tudo, já".

Este matema-matriz, assim como todos os demais, é composto por quatro elementos $\left(\mathrm{S}_{1}\right.$ - significantemestre, $S_{2}$ - saber, a - objeto causa de desejo, e $\$$ - sujeito -barrado, o falasser), quatro lugares fixos (agenciador/semblante, trabalho/gozo, produto/mais de gozar e verdade ${ }^{3}$ ) e dois campos (a saber, o campo do sujeito e o campo do outro):

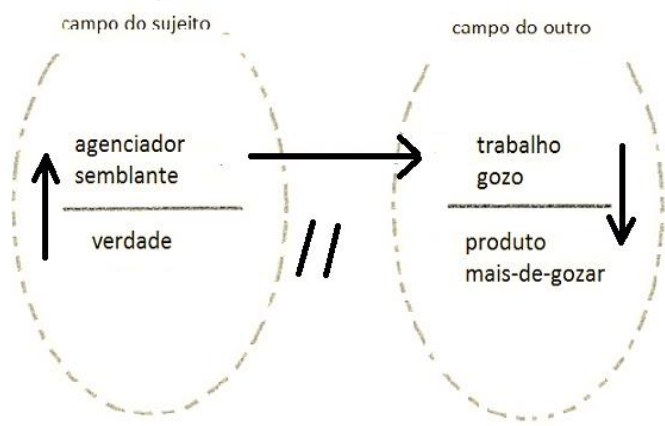

Com o giro no sentido horário dos quatro elementos, mantida sua ordenação relativa, chega-se aos três outros discursos: discurso da histérica (DH), discurso do analista (DA) e discurso universitário (DU).

Com relação ao discurso universitário, embora o laço universitário transcenda muito o ambiente acadêmico, o matema está calcado no binômio professor-aluno e formaliza a chamada "nova tirania do saber" (TUDANCA, 2008, p. 94). Não um saber qualquer, mas uma "falsa ciência", uma "ideologia da ciência" ou mesmo qualquer ideologia ${ }^{4}$. Com efeito, $\mathrm{S}_{2}$ é o semblante deste saber burocraticamente organizado. Sob a barra do recalque, encontra-se a verdade deste laço: um significante-mestre. No ideal da ciência moderna, o seu sujeito, aquele que o elabora e a sua posição, deve ser anulado. Em outras palavras, o discurso universitário, a ideologia da ciência moderna, está calcado em sua pretensa neutralidade.

Instalado no lugar do trabalho encontra-se o astudado, como chama Lacan ao estudante universitário, puro objeto, mera "unidade de valor". Aliás, não por acaso, desde a reforma universitária brasileira de 1968,

${ }^{3}$ Ao longo de seu ensino, Lacan foi modificando a denominação de cada lugar, mantido apenas imutável o lugar da verdade.

${ }^{4}$ Daí Lacan, de maneira exagerada ou equivocada, penso, tenha atribuído o DU a Lenin. 
inspirada no modelo estadunidense, cabe ao astudado, ou seja, ao aluno ${ }^{5}$, acumular créditos para fazer jus ao seu diploma. Créditos esses que são obtidos a partir da sua posição de objeto do discurso (do professor) universitário. Nessa perspectiva, portanto, não há que se falar que o aluno estuda, pois, na verdade, o aluno decora (TUDANCA, 2008, p. 95).

Resultado do agenciamento do professor, representante do saber congelado sob a forma de ideologia, de falsa ciência, um clichê, enfim, sobre o aluno, produz-se um sujeito castrado, descolado do significantemestre, que sustenta esta produção em série de simulacros de seu senhor contemporâneo. $\mathrm{O}$ saber, sob a forma de clichê, perde o seu ferrão. ${ }^{6}$

\section{O IMPOSSÍVEL E A MUDANÇA DOS DISCURSOS}

Grosso modo, pode-se associar os quatro discursos às chamadas três profissões "impossíveis", nas quais o fracasso é, de antemão, garantido, lembradas por Freud (FREUD, 1937/2006; CIFALI, 2009). Profissões certamente impossíveis, mas nem por isso impraticadas. Ou seja, os discursos seriam formas de se lidar com algo da ordem do impossível (LACAN, 1970/2003, p. 443-446).

Seguindo na homologia entre os discursos e as profissões impossíveis, poderíamos ter o governar representando o DS, o educar ${ }^{78}$ pelo DU, enquanto o curar/analisar representaria o discurso do analista. Restaria o discurso da histérica, o qual tomaremos neste texto como uma possível representação de inquirir, pesquisar ou, ainda, fazer ciência/cultura. Aliás, Lacan, em Radiofonia e outros textos, associa claramente a ciência ao DH.

Ora, precisamente porque são profissões, ações, discursos, laços existentes, mas que contêm algo de impossível, sempre fracassam e, portanto, dão lugar a outros laços. Em outras palavras, os discursos giram, cada um fracassa e dá lugar a um outro laço. A impossibilidade é ponto arquimediano para mover os discursos. Enfim, algo se move.

Nos termos do matema, o produto não elucida a verdade do discurso. Para isso, precisamos do discurso do analista. Eis o furo do discurso: a verdade nunca é completa, pois nunca pode ser completada pelo seu próprio produto.

\section{DO DISCURSO DO SENHOR AO PSEUDODISCURSO CAPITALISTA: UM TRUQUE}

Conforme foi estabelecido, do quadrípode lacaniano é formalmente impossível deduzir um quinto discurso. Contudo, já no Seminário 16, antes, portanto, da formalização dos quatro discursos, Lacan aborda explicitamente o discurso capitalista: “A mais-valia, portanto, é fruto dos meios de articulação que constituem o discurso capitalista. É o que resulta da lógica capitalista" (LACAN, 1968-69/2008, p. 37). No Seminário 17, Lacan alude a um outro discurso que não faria laço social. Este discurso paradoxal pode ser representado pelo pseudodiscurso capitalista (DC). Apesar de anunciá-lo, Lacan não entregou sua escrita até 1972, em Milão (LACAN, 1972).8

Para Lacan, o pseudodiscurso capitalista é uma transformação, via um "truque", sobre o discurso do senhor. O truque teria sido viabilizado pelo discurso universitário.

Em Margin Call, uma cena ilustra bem esta passagem. Trata-se de uma reunião, dirigida por Jared Cohen (JC), que tem como propósito discutir a análise de risco elaborada por Peter Sullivan (PS), a partir de gráficos etc. Sara Rogers (Demi Moore), analista de risco sênior do banco, dirigindo-se a Sullivan, pergunta sobre sua experiência e currículo.

PS: Estou na firma há dois anos e meio, trabalhando com Eric, mas tenho doutorado em engenharia, especializado em propulsão pelo MIT e graduação pela Penn.

JC: E o que seria especialização em propulsão?

${ }^{5}$ Aluno, do latim, alumnus,i: "criança de peito, lactente, menino, aluno, discípulo" (Houaiss Eletrônico, 2009). Ou seja, em nossa língua, poderíamos dispensar o neologismo lacaniano astudado.

${ }^{6}$ Será coincidência que Freud (1919/2006), questionando a conveniência de se ensinar psicanálise na universidade, logo inverte a pergunta e conclui que nada se ganharia com isso?

${ }^{7}$ Mantenho o verbo, posto que Freud assim o fez. Contudo, considerando-se o debate contemporâneo do campo educacional marxista, seria mais adequada a utilização, neste caso, do verbo "treinar" ou "adestrar".

${ }^{8}$ Segundo Alberti (s/d, p. 5), a última referência ao discurso capitalista está em Televisão (LACAN, 1974/2003). 
PS: Minha tese foi um estudo sobre como as taxas de fricção afetam o uso aeronáutico sob gravidade reduzida. JC: Então, você era cientista aeroespacial?

PS: Eu era.

JC: Hum. Interessante. Como veio parar aqui?

PS: Na verdade, é tudo número. Só muda o que você adiciona. Falando abertamente, o dinheiro aqui é consideravelmente mais atrativo.

Marx (1890/1994, vol. I., cap. XIII) mostra claramente uma mudança operada no pensamento ocidental. Se a ciência grega clássica aspirava à mera contemplação, a Revolução Industrial inglesa (em torno de 1780) representou a transformação da ciência, notadamente da matemática, da física e da química, de potência espiritual em potência material, ou seja, possibilitou a conversão da ciência em força produtiva. Marx, ao escrever e anunciar o saber sobre a exploração capitalista, ao lhe apontar sua verdade, a mais-valia, também esclareceu o próprio capitalista disso. A verdade foi, talvez, naturalizada.

Para Aflalo (2008, p. 83), se, em 1970, Lacan define o Inconsciente como o próprio discurso do senhor, em 1972 também o associa ao discurso capitalista. O Inconsciente seria o trabalhador ideal, pois trabalha sem senhor, sem pensar, sem julgar ou calcular. No laço social conhecido como discurso do senhor, onde o mundo é governado por uma Lei, ou aquilo que no campo do Direito é conhecido como direito consuetudinário, neste laço, em alguma medida, ambos perdem e ambos ganham - senhor e escravo. $O$ escravo sabe, trabalha e assim goza. $O$ senhor embora recolha os produtos do laço, não os acumula. A rigor, o resto é jogado fora. $O$ Inconsciente trabalharia apenas a produção do gozo, um gozo perdido. $O$ produto é resto.

Contudo, a emergência e posterior dominância das práticas sociais capitalistas, isso que era deixado como resto, passa ser considerado desperdício absurdo e, portanto, deve ser reintroduzido no circuito da mercadoria. Eis a chamada Lei do Valor, de Marx - $D \rightarrow m \rightarrow D^{\prime}$-, circuito infernal onde o valor acrescido só serve para acrescentar mais-valor ao próprio valor.

Com o discurso do mestre [i.e. do senhor], o aparelho significante faz brotar um mais de gozar do corpo. E com o discurso capitalista, a produção e a exploração do objeto a mais-de-gozar são impelidas até o frenesi. (AFLALO, 2008, p. 84)

Contudo, neste giro infinito se consomem os recursos naturais e, sobretudo, o tempo de vida daqueles dos quais é extraída a mais-valia. Aliás, valor é tempo de trabalho acumulado (MARX, 1890/2013, p. 270).

Se há, portanto, um imperativo categórico, este é "goze", "acumule". Tal imperativo, a rigor, não vem do capitalista, do Self made man, mas diretamente da verdade do pseudodiscurso. Assim soa aos ouvidos do proletário moderno $\left(\mathrm{S}_{2}\right)$. O produto do laço não é propriamente consumido, posto que é destinado a realimentar o circuito, curtocircuitando-o.
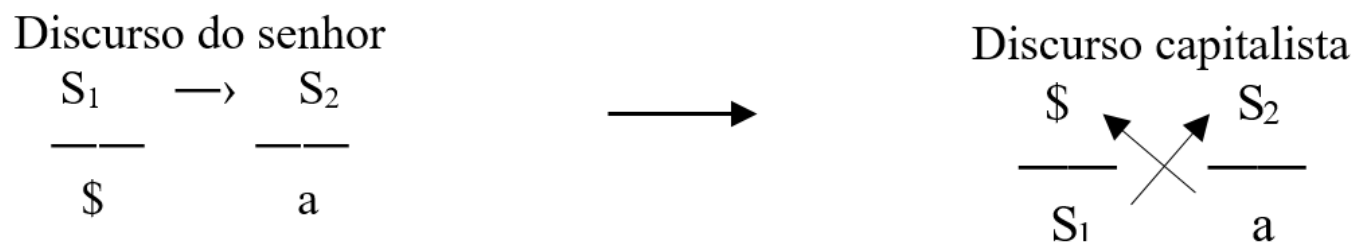

Se, no discurso do senhor, a verdade de sua castração está velada, no laço capitalista o burguês é um falasser qualquer, castrado mesmo (\$). Daí imaginariamente se produzir a ideologia de que também o servo moderno poderia passar a ocupar o lugar deste senhor moderno, ou seja, daquele que recebe o produto do trabalho. Com esse truque, $\mathrm{S}_{2}$ é capturado na identificação a \$. Todos poderiam ganhar, isto é, acumular, isto é, gozar.

É como se pudéssemos dizer: o discurso capitalista não exige renúncia pulsional, ao contrário, ele instiga à pulsão, impondo ao sujeito determinadas relações com a demanda, sem se dar conta de que, ao fazê-lo, sustenta sobretudo e em primeira mão, a pulsão de morte. (ALBERTI, s/d, p. 8) 
Contudo, na medida em que se amplia a acumulação, a taxa de exploração tende a decair, pois, para ampliar esta taxa, o capitalista se utiliza da tecnologia, isto é, da substituição do trabalho vivo pelo trabalho morto. Posto que é o trabalho vivo a fonte do valor, ao ser continuamente substituído reduz-se continuamente e - contraditoriamente - a base mesma da acumulação. Em outras palavras, o limite da acumulação é a própria acumulação (MARX, 1890/1994, vol. II, p. 712-827).

Lacan, por sua vez, concordando mais uma vez com Marx, diz em Milão, tratando do discurso capitalista:

Loucamente astuto, porém condenado a rebentar.

Enfim, é depois de tudo isso que o fizemos mais inteligente como discurso. Não é menos condenado a rebentar. É que é insustentável. É insustentável... um truque que eu poderia Ihes explicar... porque, o discurso capitalista é aqui, vocês vêem [...] simplesmente uma pequena inversão entre o $S_{1}$ e o $S . .$. que é o sujeito.... é suficiente àquilo que anda como que sobre rodas, não precisa andar melhor, mas justamente anda muito rápido, se consome, se consome de modo que se consuma. (LACAN, 1972, p. 13)

Nesse sentido, vale lembrar o alerta, de Marx e Engels, logo no início de O manifesto comunista:

A história de todas as sociedades de classe até hoje existentes é a história da luta de classes.

Homem livre e escravo [...], opressores e oprimidos, em constante oposição, têm vivido numa guerra ininterrupta, ora franca, ora disfarçada; uma guerra que terminou sempre ou por uma transformação revolucionária da sociedade inteira, ou pela destruição das duas classes em conflito. (MARX; ENGELS, $1848 / 1998$, p. 40 , grifos nossos)

De fato, o laço se consome em chamas, em graves sintomas sociais.

\section{O DISCURSO DO SENHOR COMO SUSTENTÁCULO DO DISCURSO CAPITALISTA}

Se concordarmos que o discurso capitalista é insustentável, ou seja, é na verdade um pseudodiscurso, algo mais precisa estar presente para que ele siga em frente até queimar. Parece-me que a cena a seguir ilustra a resposta.

Cena: um tanto reticente, Sam Rogers reúne os operadores, isto é, os profissionais que tentarão salvar a firma vendendo todos os ativos podres que estão no portfólio dela. Sam, de pé, diante dos operadores sentados ao redor de uma grande mesa, começa explicando o que todos devem fazer: vender tudo. As coisas vão piorar etc. E que a firma decidiu começar o tumulto geral no mercado.

Com certeza, não se demora muito para entender as consequências desta venda em suas relações com suas contrapartes e, como resultado, em suas carreiras. Já expliquei esta realidade ao comitê executivo e eles compreendem. Como resultado, se atingirem uma venda de $93 \%$ de seus ativos, receberão 1,4 milhão de dólares de bônus. Se todo o andar atingir $93 \%$ de venda, cada um receberá um bônus de 1,3 milhão. [...] Quero que vão para cima de todos, revendedores, corretores, clientes. A sua mãe, se ela for comprar. E, sem trocas. É só venda, hoje. [...]

Isso não saiu como todos gostaríamos. Mas, o chão está se movendo sob os nossos pés. E aparentemente não há outra saída. [Grifos nossos.]

Tudo irá queimar. O próprio sistema financeiro mundial está à beira do abismo. Eis o pseudodiscurso capitalista. Após uma interminável pausa de 20 segundos, Sam Rogers, cansado, senta-se, tira os óculos, arfa e muda o tom:

Pessoal, esta é obviamente uma situação única. Se tivermos sucesso hoje, teremos sucesso na destruição de nossos próprios empregos. Eu não posso prometer que qualquer um venha a ser recolocado na firma. Mas, eu posso dizer que estou muito orgulhoso do trabalho que fizemos juntos. Estou neste lugar há 34 anos. E, pela experiência, posso dizer que dirão coisas horríveis sobre o que estamos fazendo hoje e sobre aquilo que se dedicaram parte de suas vidas... Mas, tenham fé, numa perspectiva mais ampla, nossas habilidades não serão desperdiçadas. Conquistamos muitas coisas. Nosso talento foi usado para o bem maior. [...] Ao trabalho. [Grifos nossos.] 
Todos se levantam e vão iniciar o fim do mundo, queimar o estoque, consumir seus próprios empregos, destruir a vida de milhões, mundo afora. As cenas seguintes retratam o título mesmo do filme: ouvimos as margin calls. ${ }^{9}$

Dois discursos estão entrelaçados com vistas à manutenção da firma, isto é, da valorização do valor. Primeiramente, de forma cínica, o executivo demonstra que se a empresa ganhar com aquela ação tresloucada, então, todos aqueles operadores, serão bem pagos. Contudo, é óbvio que se a queima de estoque for bem realizada por eles, o laço capitalista, o vínculo empregatício, também será consumido, não só agora mas talvez para sempre. Mas, mesmo assim, todos põem-se em trabalho. Como assinalou diversas vezes Žižek, ao contrário da frase bíblica, "fazem sem saber", aqui, sabem e mesmo assim fazem. Mas, por que o fazem? (ŽIŽEK, 1992; SAFATLE, 2008 e 2010) ${ }^{10}$

Em seguida, ao discurso capitalista, o executivo, agora melancólico, exorta-os, vocalizando a Lei: "Nosso talento foi usado para o bem maior e não será desperdiçado. Tenham fé".

Não se sabe que bem maior seria. Insondáveis são os caminhos postos pela Lei. O discurso do senhor põe todos a trabalhar. Talvez queiram acreditar que encarnem um saber útil ao senhor e, sendo assim, de alguma forma, serão poupados. Afinal, sem eles, o Grande Outro também não poderia existir. Suturar a falha do Grande Outro, eis o papel de cada um. Para insistir na repetição mortífera, o pseudodiscurso capitalista precisa, portanto, se apoiar sobre o discurso do senhor.

Em síntese, o pseudodiscurso capitalista é incapaz de - por si só - permanecer estável, funcional, por muito tempo. Queimado rapidamente, é preciso apoiar-se no antigo discurso do senhor.

\section{RUMO À ESTAÇÃO FINLÂNDIA}

Sabemos que os discursos deslizam, que o pseudodiscurso capitalista anda rápido, consumindo, se consumindo, queimando, enfim, o próprio laço social. Uma metáfora adequada seria a do circuito elétrico que se rompe, precisamente pelo aumento instantâneo e insustentável da corrente. Para permanecer repetindo sua própria autocombustão, o pseudodiscurso capitalista precisa, portanto, se apoiar sobre o discurso do senhor, primariamente, e também no discurso (ideológico) da ciência, secundariamente.

Em outra cena, angustiado com a demissão dos operadores que realizaram a tarefa que lhes foi confiada, Sam Rogers indignado vai ao encontro do grande senhor John Tuld, que está fazendo uma refeição, no alto do prédio da firma, de onde se vislumbra toda cidade de Nova lorque. Chega Rogers e Tuld recebe-o com euforia e o agradece pelo trabalho infernal que realizou e lhe pergunta em que pode ajudar. Resposta de Rogers: "Eu me demito". A partir daí, segue um debate sobre a pertinência e utilidade de tudo aquilo:

JT: Você é um dos caras mais sortudos do mundo, Sam. Poderia estar cavando valas esses anos todos.

SR: Isso é verdade. Pelo menos teríamos alguns buracos no chão para os enterros. Não sei como ferramos com tudo desse jeito.

JT: Quando começou com essa autopiedade? É insuportável. Então, acha que colocamos algumas pessoas fora dos negócios hoje. E que tudo é em vão. Mas você faz isso todos os dias há 40 anos, Sam. E se é tudo em vão,

9 Literalmente, margin call significa "pedido de cobertura", e o termo parece ter surgido porque, antigamente, corretores telefonavam para clientes pedindo maior cobertura de capital para algum investimento. Na prática, significa que os operadores de mercado procuram reduzir o que se chama de grau de alavancagem (volume de capital de terceiros, que não pertence à empresa, sobre o total dos investimentos que foram realizados), colocando mais recursos próprios. Às vezes, isso é necessário porque a legislação exige um mínimo de cobertura para investimentos. Quando ele não é atingido, faz-se a margin call. Outras vezes, independente de exigência legal, quando o risco da operação é excessivamente elevado), faz-se também a margin call. (Devo esta explicação a Marcelo Carcanholo).

${ }^{10}$ Safatle, particularmente no capítulo A clivagem do Eu e seus descontentes, no qual o autor discute as noções de fetichismo na psicanálise e no marxismo, incluindo neste debate um questionamento à utilização das temáticas da reificação e da falsa consciência: "Mas talvez precisemos refletir sobre modelos de alienação que viabilizem uma crítica do fetichismo social não mais dependente dessas temáticas da reificação e da falsa consciência. É possível que a compreensão do fetichismo social nos exija um abandono da temática da reificação da essência na dimensão da aparência fantasmática do processo de determinação de valor ou da imagem como bloqueio da reconstrução do sentido como totalidade" (SAFATLE, 2010, p. 129). 

da teoria dos discursos lacaniana e da crítica da economia política marxiana

então, todo o resto também é. É apenas dinheiro. É inventado. Pedaços de papel com imagens para não termos que matar uns aos outros para ter o que comer. Não é errado. E certamente não é diferente hoje do que sempre foi: 1637, 1767, 1819, 1837, 1857, 1884, 1901, 1907, 1929, 1937, 1974, 1987. Jesus. Aquele cretino não me ferrou legal? 1992, 1997, 2000 e qualquer coisa que quisermos chamar. É tudo a mesma coisa, sempre. Não podemos evitar. E você e eu não podemos controlar ou impedir, nem mesmo desacelerar. Quando muito, alteramos de leve. Nós só reagimos. E ganhamos muito dinheiro quando fazemos certo. E somos largados na beira da estrada se fizermos errado. E sempre houve e sempre haverá o mesmo percentual de ganhadores e perdedores. Gente feliz, gente triste. Gatos gordos e cachorros famintos, no mundo. Bem, talvez haja mais de nós hoje do que nunca. Mas os percentuais continuam exatamente os mesmos.

Enquanto Tuld exerce cinismo da razão, que culmina com o convite de permanecer na firma, Rogers vai da irritação contida à melancolia e, então, a um leve sorriso de satisfação. Confrontou o senhor, mas, no final, o sorriso de satisfação, não por que o derrogou, ao contrário, pois ele continua lá, onde sempre esteve. Então, levanta-se e diz, docemente constrangido:

SR: Vou fazer, John, mas não por causa de seu discursinho. Mas porque preciso do dinheiro. Difícil de acreditar após todos esses anos, mas... preciso do dinheiro.

Tudo foi desmascarado. Mas, tudo precisa continuar exatamente do mesmo jeito. Seja porque o senhor assim garante a existência do escravo, seja porque o escravo acredita que também poderá chegar a ocupar o lugar do senhor. A insistência no desempenho dos respectivos papéis tranquiliza a tragédia burguesa: Eu sei, mas, mesmo assim, continuo fazendo ${ }^{11}$ : preciso do dinheiro. Fetiche social supremo.

O filme termina com o som de uma escavação. Quase como que numa atuação, Sam Rogers cava uma sepultura para o seu cão, no quintal de sua ex-mulher.

Dentre tudo o que falta saber-fazer, poder-se-ia, neste contexto, apontar para a pergunta: qual seria uma possível saída do pseudodiscurso capitalista?

A mera instauração de um laço que reproduza um saber já constituído, bem organizado, mesmo que seja o saber marxista ${ }^{12}$ sobre o modo de produção capitalista, até o momento não rendeu os frutos necessários à superação da sociedade em que impera a lei do valor. Na melhor das hipóteses, tal saber apenas consegue operar uma crítica positiva das relações capitalistas, que poderia ser assimilada a um laço de tipo histérico. Em outras palavras, se o saber produzido por Marx, petrificado sob a forma ideologia não vem sendo capaz de realizar o Aufhebung do pseudodiscurso capitalista, nem mesmo do discurso do senhor, cabe, em primeiro lugar, retomar a crítica negativa da sociedade capitalista, ${ }^{13}$ tal qual foi desenvolvida por Marx.

Talvez seja sobre a base da crítica negativa que possamos nos preparar para a possibilidade do ato ou corte como o de Lenin, na noite de 3 de abril de 1917, na estação Finlândia de Petrogrado. O ato de Lenin pode ser assimilado ao que Lacan denominou de ato analítico (LACAN, 1974/ 2003, p. 529), e formalizado no matema do discurso do analista.

Com efeito, Lenin, do alto de um carro blindado, naquela estação de trem e no dia seguinte diante de delegados bolcheviques e mencheviques do Soviet, provocou um corte com todo saber anterior, ao declarar: Todo poder aos Soviets (LÖWY, 1985, p. 126).

${ }^{11}$ Aqui se precisa fazer um alerta. Em Margin call, a classe trabalhadora está completamente silenciada. Salvo engano, só está representada na figura de três personagens, sem falas: uma faxineira, um manobrista e um contínuo. Tal eloquente ausência seria fruto da compreensão de que o capital financeiro se auto nomizou (da exploração) do trabalho vivo? Todas as demais personagens do filme pertencem à burguesia ou a setores médios em vias de serem incorporados à burguesia.

12 Há diversas leituras e práticas políticas marxistas. Obviamente, nos referimos aqui àquelas que se transformaram em dogmatismo, dentre as quais a mais comum e deletéria é, sem dúvida, a forma stalinista. Dentre as leituras renovadoras, de retorno a Marx, destaco, no contexto deste texto, a obra de Bensaïd, particularmente, Marx, o intempestivo (BENSAÏD, 1999).

13 A crítica negativa é aquela que, essencialmente descobre, na estrutura necessária da realidade posta (a positividade), possibilidades não objetivadas, mas efetivas como possibilidades. No caso do capitalismo, uma crítica desta natureza poderia revelar, em sua forma direta de manifestação ("aquilo que está"), não apenas outras formas de expressão do mesmo conteúdo ("aquilo que permanece", em outra forma), mas também possibilidades de transformação em algo realmente distinto ("aquilo que está" superado, transformado em "outra realidade"). (Devo esta definição a João Leonardo Medeiros.) 
"As palavras de Ilitch abriram um Rubicão entre as táticas de ontem e as de hoje" (citado por WILSON, 1940/1987, p. 442). O ato produziu um salto sobre todas as contradições insolúveis daquela realidade petrificada e, assim, abriu a possibilidade da emergência do novo.

Mas, o próprio Lacan adverte:

Quanto mais somos santos, mais rimos, esse é o meu princípio, ou até mesmo a saída do discurso capitalista - o que não constituirá um progresso se for apenas para alguns. (LACAN, 1974/2003, p. 519)

Enfim, a práxis da transformação precisa ser sustentada por muitos e para muitos, sem o qual poderá se virar pelo avesso. Travessia.

Recebido em: 18 de janeiro de 2015. Aprovado em: 27 de maio de 2015

\section{REFERÊNCIAS}

AFLALO, A. Discurso capitalista. In: AMP (Associação Mundial de Psicanálise). Scilicete: Os objetos $a$ na experiência psicanalítica. Rio de Janeiro: Contra Capa, 2008.

ALBERTI, S. O discurso do capitalista e o mal-estar na cultura. [s/l, s/d]. Disponível em: <http://www.scribd.com/doc/19133239/Sonia-Alberti-O-Discurso-Do-Capitalist-A-e-o-Mal-Estar-NaCultura>. Acesso em: jun. 2012.

BECKER, P. A economia do gozo: Freud, Marx e Lacan. Rio de Janeiro: Garamond, 2010.

BENSAÏD, D. Marx, o intempestivo: grandezas e misérias de uma aventura crítica (séculos XIX e XX). Rio de Janeiro: Civilização Brasileira, 1999.

BERNARDES, A. C. Tratar o impossível: a função da fala na psicanálise. Rio de Janeiro: Garamond, 2003.

CALDAS, H. Discurso da histérica. In: AMP (Associação Mundial de Psicanálise). Scilicete: Os objetos $a$ na experiência psicanalítica. Rio de Janeiro: Contra Capa, 2008.

CIFALI, M. Ofício “impossível”?: piada inesgotável. Educação em Revista. Belo Horizonte, v. 25, n. 01, abr., 2009.

FREUD, S. Análise terminável e interminável (1937). Rio de Janeiro: Imago, 2006. (Ed. standard brasileira das obras completas, 23).

. Moisés e o monoteísmo (1939). Rio de Janeiro: Imago, 2006. (Ed. standard brasileira das obras completas, 23).

. O mal-estar na civilização (1929). Rio de Janeiro: Imago, 2006. (Ed. standard brasileira das obras completas, 21).

Psicologia das massas e análise do eu (1921). In: Psicologia das massas e análise do eu e outros textos (1920-1923). São Paulo: Companhia das Letras, 2011.

Sobre o ensino da psicanálise nas universidades (1919). Rio de Janeiro: Imago, 2006. (Ed. standard brasileira das obras completas, 17).

Totem e tabu (1913). Rio de Janeiro: Imago, 2006. (Ed. standard brasileira das obras completas, 13).

GELLER, S. Discurso do mestre. In: AMP (Associação Mundial de Psicanálise). Scilicete: Os objetos $a$ na experiência psicanalítica. Rio de Janeiro: Contra Capa, 2008.

HEGEL, G. W .F. Fenomenologia do espírito (1807). 2 partes. Petrópolis: Vozes, 1992.

LACAN, J. De um Outro ao outro (1968-1969). Rio de Janeiro: Jorge Zahar, 2008a. (O seminário, 16).

La conferencia de Lacan en Milán del 12 mayo de 1972. Disponível em $\overline{<h t t p: / / p t . s c r i b d . c o m / d o c / 55454317 / C O N F E R E N C I A-D E-L A C A N-E N-M I L A N-D E L-12-D E-M A Y O-D E-~}$ 1972>. Acesso em: jun. 2012.

Mais, ainda (1972-1973). Rio de Janeiro: Jorge Zahar, 2008. (O seminário, 20).

O avesso da psicanálise (1969-1970). Rio de Janeiro: Jorge Zahar, 1992. (O seminário, 17).

Radiofonia (1970). In: . Outros escritos. Rio de Janeiro: J. Zahar, 2003. 


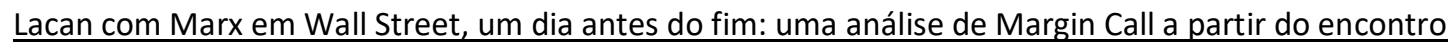
da teoria dos discursos lacaniana e da crítica da economia política marxiana

Televisão (1974). In: Outros escritos. Rio de Janeiro: J. Zahar, 2003b.

LÖWY, M. Da Grande Lógica de Hegel à estação finlandesa de Petrogrado. In: Método dialético e teoria política. 3a ed. Rio de Janeiro: Paz e Terra, 1985

MARX, K. O capital: crítica da economia política. Livro I: o processo de produção do capital (1890). São Paulo: Boitempo, 2013.

SAFATLE, V. Cinismo e falência da crítica. São Paulo: Boitempo, 2008.

Fetichismo: colonizar o Outro. Rio de Janeiro: Civilização Brasileira, 2010.

SOUEIX, A. O discurso capitalista. In: GOLDENBERG, Ricardo (org.). Goza!: capitalismo, globalização e psicanálise. Salvador: Álgama, 1997.

TUDANCA, L. Discurso universitário. In: AMP (Associação Mundial de Psicanálise). Scilicete: Os objetos $a$ na experiência psicanalítica. Rio de Janeiro: Contra Capa, 2008.

WILSON, E. Rumo à estação Finlândia: escritores e atores da história (1940). São Paulo: Companhia das Letras, 1987.

YACOI, A. Discurso do analista. In: AMP (Associação Mundial de Psicanálise). Scilicete: Os objetos $a$ na experiência psicanalítica. Rio de Janeiro: Contra Capa, 2008.

ŽıŽEK, S. Eles não sabem o que fazem: o sublime objeto da ideologia. Rio de Janeiro: Jorge Zahar, 1992.

José Rodrigues

jrodrigues21@gmail.com 